\title{
FRANCISCO DE CASTRO CANSECO (Ca. 1655-1714), EN LA ACTIVIDAD ARTISTICA DE GALICIA
}

\author{
por Jose Manuel Garcia Iglesias \\ Universidad de Santiago de Compostela
}

\begin{abstract}
Este artista, de origen leonés, acomete diversos trabajos importantes como entallador y escultor también como arquitecto-, en el tránsito del XVII al XVIII. Primero en Sobrado dos Monxes y, más tarde, en Celanova, Tui, Ourense y Oseira, desarrolla importantes obras. la importancia de su quehacer lleva a las monjas benedictinas compostelanas de San Paio a encargarle nada menos que su retablo mayor.
\end{abstract}

This artist, originally from León, undertook several important projects as sculptor and engraver and also as an architect- in the 17th and 18th centuries. First in Sobrado dos Monxes, and later in Celanova, Tui, Ourense and Oseira, he carried out major works. His renown prompted the Benedictine nuns of San Paio, in Santiago de Compostela, to commission their main altar-piece from him.

Nació en Valderas, un pueblo leonés. Opina Caramés que su nacimiento debió de ser hacia el año 1655; se basa para ello en lo que se dice en un pleito de 1722 en el que Castro declara "ser de sesenta y seis años, poco más o menos" 1

Ultimamente se ha publicado una parte del Libro Becerro de Sancti Spiritus de Melide, del año 1662; allí se dice : "Esta casa de la partida de abaxo que es la de Tomás se arrendó el año de ntb. ta. al Maestro Franco de Castro por nueve años y seis D.s de Venta... (fol 14)" ${ }^{2}$. De ser cierta la edad señalada en el citado pleito el escultor Canseco tendría, por entonces, siete años.

Pero lo que resulta evidente es que en 1662 hay un artista en Melide que se llama Francisco de Castro que debió de ser pariente del que aquí se trata - ¿su

1. C. CARAMES GONZALEZ : El escultor y entallador Francisco de Castro Canseco (16931724). "Boletín Auriense", II (1972), 167.

2. X. M. BROZ REI : Apéndice documental: Libro Becerro de Sancti Spiritus: parte. "Boletín do Centro de Estudios Melidenses. Museo da Terra de Melide", 116. 
padre?-. Otros Castro, citados en este lugar, pueden, muy bien, ser miembros de una misma familia. Esa infancia en tierras melidenses facilita, por otra parte, la justificación de una peculiaridad de su arte que se hará evidente desde un primer momento: su nexo con la actividad artística compostelana.

El testamento de Castro Canseco nos da un dato sobre su etapa de juventud: “antes de casarse... él y su hermano, el capitan Alonso de Castro y Canseco, hicieron donación de sus legítimas, tanto paterna como materna, a favor de su hermana doña Mariana de Castro" ${ }^{3}$.

Va a casarse en su pueblo natal con D. ${ }^{\text {a }}$ Isabel Montero. En 1687 bautizaba, también en Valderas, una hija. Pronto ha de desplazarse a Melide ya que debe de contratar el retablo mayor de la iglesia conventual de Sancti Spiritus hacia 1690.

\section{SU VECINDAD EN MELIDE ANTERIOR A 1695}

Tal asentamiento en Melide debe de justificarse por razones de carácter familiar que tienen su base documental en esa señalada cita alusiva a un Maestro Francisco Castro, anterior a éste. En este lugar tiene su casa y llega a poseer unas notables propiedades ${ }^{4}$; se sabe, por ejemplo que, años más tarde, el artista tuvo que vender "cantidad de vienes y renta en el lugar y tierra de Mellide..." 5.

La data del retablo mayor del convento de Sancti Spiritus se deduce de una referencia documental; en un pleito de 1705 se hace referencia a la colocación de tal retablo mayor hace unos 14 años ${ }^{6}$. La obra en cuestión resulta perfectamente integrable en el quehacer de Castro en lo que se refiere a su cuerpo bajo, con tres calles, y parte central de la superior, en tanto las zonas laterales altas responden a otro estilo. El modo de poner especial énfasis en la zona media del conjunto se encuentra muy en la línea del trabajo del maestro, especialmente localizable en el modo de representar la escena de Pentecostés, en lo alto.

Así mismo Broz vincula con Canseco, en esta misma iglesia, una imagen de la Verónica y un retablo dedicado a S. Antón, del que hoy tan solo se conservan dos columnas que siguen características propias de este maestro ${ }^{7}$.

3. C. CARAMES GONZALEZ : El escultor ..., 166.

4. Allí compra, en 1694, el lugar de Ribeiro en Santa Maria de Melide (P. PEREZ COSTANTT: Diccionario de Artistas que florecieron en Galicia durante los siglos XVI y XVII. Santiago, 1930, 94).

5. C. CARAMES GONZALEZ : El escultor ..., 168.

6. X. M. BROZ REI: O Mosteiro de Sancti Spiritus de Melide: 3 etapas de construcción. "Boletín do Centro de Estudios Melidenses. Museo da Terra de Melide", 45.

7. X. M. BROZ REI: $O$ Mosteiro ..., 76-77. 
Y siendo vecino de Melide contrata con los monjes de Sobrado para "hacer de escultura, los tableros de medio relieve de las sillas altas que se están haciendo para el coro de dho monasterio, que tenía ajustados cada uno en setenta reales... y cada y quando que le dieren dhos tableros puestos en su casa de morada en dha villa de Mellid" ". Puede ser que tuviese hecho 35 temas en 1694 dado que, en las cuentas de Sobrado, hay un pago al "escultor" por el que "a este se le han dado dos mill y quatrocientos reales a quenta de la escultura de los santos para el Coro.. 2.400 reales" 9. cantidad que puede corresponderle a este maestro.

\section{1695-1700: ESTANCIA EN CELANOVA}

El hecho de que los cistercienses de Sobrado se viesen obligados a cambiar de escultor, para la obra de su coro, allá por 1695 , coincide con la marcha del maestro a Celanova donde va a asentar, en ese momento, su casa. Así, cuando se le contratan, por 1696, diversas obras de importancia para la capilla del Santo Cristo de la Catedral de Ourense, se tiene en cuenta que la obra se ha de realizar en Celanova, por lo cual se ha de hacer el pago del porte correspondiente, hasta Ourense, en $1697^{10}$. Debe de trabajar en Celanova al menos hasta 1699 ya que, en ese momento, no había trasladado su casa a Ourense; ello se deduce del contrato que firma a principios de ese año con representantes del cabildo catedralicio tudense, donde se le cita como "Maestro de Arquitectura vezino de la villa de Mellid" "'.

Debe de tenerse en cuenta que,por 1699, es obispo de Tui, un fraile benedictino vinculable con Celanova, Fr. Anselmo Gómez de la Torre; Hipólito de Sá recuerda el hecho de que este prelado, en el año 1721, "se retiró al Monasterio de Celanova, en donde murió en olor de santidad" 12 .

Ha de tenerse en cuenta que el contrato tudense no conlleva exigencia de residencia para el maestro que se titula arquitecto y que "se obligó con su persona y vienes muebles y raices avidos y por aver de Dar echa y fenecida la dha

8. P. PEREZ COSTANTI: Diccionario..., 94.

9. P. GONZALEZ LOPEZ: Valoración del fondo documental del Archivo del Reino de Galicia relativo a la actividad artística de los Monasterios Cistercienses. 1498-1834. (Santiago, 1986). Tesis de Licenciatura Inédita, 264.

10. J. FERRO COUSELO, J. LORENZO FERNANDEZ: La Capilla del Sto. Cristo de Orense. "Boletín del Museo Arqueológico Provincial de Orense", I (1943), 39.

11. E. IGLESIAS ALMEIDA: Arte y Artistas en la antigua diócesis de Tui. Tui, 1989, 151.

12. H. DE SA: El monasterio de Celanova. León, 1982, 30. 
obra a satisfación del Cabildo... la qual he de dar feneçida hacavada y asentada dentro de dos años que se empieza hasentar..." 13.

Se sabe que, por 1700, "tenía el maestro Castro a su cargo la obra de una casa de la Capilla (del Santo Cristo) en 10.500 reales" ${ }^{14}$, lo cual debe de señalar ya una presencia más continuada del artista en Ourense; por otra parte, en relación con ese asentamiento en Orense debe de valorarse la noticia de que, en noviembre de 1701, "arrienda por un año a Juan de León, mercader, una bodega en la Rúa de los Arcedianos" 15.

Así pues, parece factible localizar el taller de Castro Canseco en Celanova entre 1695 y 1700 , lo cual no impide que oficiales relacionados con el maestro trabajen en diferentes lugares, siguiendo el curso de los encargos.

¿Cuál fue la razón que llevó a Castro Canseco de Melide a Celanova? La iglesia de los benedictinos se había consagrado en 1687. A partir de ese momento los monjes habrían de aspirar a enriquecer debidamente el templo con un nuevo coro y con retablos que estuviesen a la altura de la magnificencia del templo. Muy posiblemente sea el propio Pedro de Monteagudo -presente en la última fase de la obras de Celanova y crucial en la construcción de la iglesia de Sobrado dos Monxes- quien ponga en relación al maestro con los benedictinos orensanos.

La ejecución de un retablo mayor y de un coro en la gran nave de la iglesia de Celanova es razón suficiente como para trasladar su taller hasta este lugar. Es posible que sea en este momento, 1695-1700, cuando se lleven a cabo tales obras ${ }^{16}$. La propia ejecución del coro pudo ser la razón que justifica el encargo de una traza para el que se quiere hacer en Tui.

Chamoso Lamas ha vinculado el retablo mayor de Celanova con los últimos años del XVII; señala el citado autor que "por el Abazologio sabemos se construyó en 1697 y aún cuando se desconoce su autor, lo mismo que el del coro bajo, puede ser considerado como una de las obras maestras de este tipo y época en Galicia" ${ }^{17}$.

Pero más que de un retablo mayor habría que aludir, quizás, a un intento de ornamentación global de la capilla mayor. Cuatro grandes columnas salomónicas pautan, en buena medida, este espacio; responden a ese formato que Hervella reconoce como significativo del maestro: "de cinco vueltas, adornadas con vides

13. E. IGLESIAS ALMEIDA: Arte y Artistas..., 151-153.

14. J. FERRO COUSELO, J. LORENZO FERNANDEZ: La Capilla..., 41.

15. C. CARAMES GONZALEZ : El escultor ..., 170.

16. Cfr. C. CARAMES GONZALEZ : El escultor ..., 186.

17. M. CHAMOSO LAMAS: La Iglesia Conventual de Celanova y su valor representativo en el barroco gallego. "Boletín del Museo Arqueológico Provincial de Orense", I (1943), 72. 
arracimadas, ramajes a base de palmetas en los entrepaños, tallos de flores y ramilletes de palmas, búcaros con rosas... por citar lo más significativo" ${ }^{18}$.

Abajo, centrando el espacio, se presenta un tabernáculo que se independiza notoriamente del conjunto retablístico. Incluso se opta aquí por alternar, con soportes de carácter salomónico, otros que tienen la condición de estípite ${ }^{19}$; además se aligera con huecos la forma cupular que remata este pequeña, y al tiempo, grandiosa arquitectura que se diseña desde criterios de un plan central para albergar, en sus entrañas mismas, el culto eucarístico, cimentando su presencia en la realidad del sagrario.

En los basamentos de este monumental expositor puede verse una colección de representaciones en alabastro, engastadas en la madera, que aluden de una forma mayoritaria a la vida de Jesús y que inciden, sobre todo, en los temas de la Pasión; el quehacer del taller de Castro Canseco se enfrenta aquí a un material inusual; se siguen aquí criterios estéticos similares a los manejados cuando el quehacer se proyecta sobre la madera.

Debe de considerarse, por otra parte, la condición de tabernáculo que se le otorga a esta parte del conjunto y que, con cierto valor autónomo, enlaza su condición con formas ensayadas precisamente en la obra del Tabernáculo de la capilla mayor de la Catedral de Compostela, concretamente en la parte relativa a ese camarín que se asienta sobre la reliquia apostólica, da encuadre al Santiago sedente y vale como base de ese Santo Peregrino al que venera la Monarquía de España; la idea de realizar una arquitectura aligerada por una importante presencia del hueco tiene su lógico antecedente, por otra parte, en el diseño del piramidal baldaquino compostelano.

Entre los fustes de las cuatros columnas genera Castro Canseco un espacio en el que da cobijo a un tono de apoteosis sacra que se enlaza con el culto a devociones propias de Celanova. Estas tienen, por cierto, una relativa condición autónoma dentro del conjunto; ahí están, claramente independizadas entre pares de salomónicas de menor tamaño, las reliquias de San Rosendo, a un lado, y de San Torcuato, al otro, con las representaciones figurativas de tales devociones monacales, sobre los respectivos cobijos de las mencionadas reliquias.

Pero, como decimos, el espacio de los intercolumnios se torna, ante todo, canto apoteósico, que se expresa en clave mariana -Asunción/Coronación- y, fundamentalmente, cristológica; de este modo se nos muestra la Transfiguración del Señor entre los temas de la Resurrección y Ascensión, fijándose, así, en

18. J. HERVELLA VAZQUEZ: Francisco de Castro y Canseco es el Churriguera gallego. "La Región", 12 de Marzo de 1989, 4.

19. Lo novedoso de las formas lleva a pensar en que bien pudiera realizarse esta parte de la obra en una cronología relativamente posterior pero, dentro, de un plan general ya previsto previamente. 
altura, un múltiple y barroco sentido ascensional de la figura de Cristo hacia los cielos mismos.

Allí donde se dispone el entablamento que enlaza en una arquitectura única a las cuatro columnas volvemos a encontrarnos con una evocación de la capilla mayor de la catedral santiaguesa. Recordando al Santiago matamoros que Andrade había encargado a Mateo de Prado, Canseco plantea el triunfo sobre el moro desde la presencia de cuatro santos caballeros: Santiago, San Martín, San Millán y San Fernando tienen, como respectivos puntos de partida, para sus monturas, el cornisamento,encima de cada una de las cuatro columnas gigantes. $\mathrm{Y}$, desde allí,como un eco del ardor de los guerreros, se produce toda una catarata de vencidos, que son arrojados desde las alturas de esa arquitectura que, en sí .misma, es adecuado asiento de una historia que centra su contenido en hacer hincapié en la divinidad del Niño; por eso se dispone la escena de la Presentación en el Templo entre las de la Navidad y la Epifanía, en un relato sacro que contemplan incluso esos cielos abiertos que el conjunto nos muestra allá en lo alto.

La idea de búsqueda de una decoración total está, así, claramente desarrollada. El hecho de que el mensaje figurativo que se presenta en las basamentos de las columnas -los cuatro Evangelistas- se continúe en las cuatro hojas de puerta que dan paso a las dos sacristías, a los lados - cuatro Padres de la Iglesia- recalca esta pretensión bien lograda.

Desde un primer momento debió de disponerse la vieja sillería, que perteneció a la iglesia anterior, en el coro alto de la nueva; es claro que por su tamaño resultaba insuficiente y que la monumentalidad del nuevo templo exigía una nueva que, desde un principio, hubo de pensarse en disponer en la nave central, en los tramos inmediatos al crucero, en línea, pues, con la que había dispuesto arriba.

Los benedictinos de Celanova van a querer, en cierta medida, emular con esta obra -habitualmente de carácter prioritario en un templo monástico- a sus hermanos de San Martiño Pinario. Tiene dos niveles de sillas y se abre por su frente no rompiendo, de este modo, la visión del altar mayor desde los pies de la iglesia.Su mitad del lado sur configura el "Chorus abatis" en tanto que, enfrente se dispone el "Chorus prioris". Las sillas del abad y del prior se disponen hacia el centro, a los lados de ese paso central que enlaza la visión desde la puerta con el altar mayor ${ }^{20}$.

En la parte alta se muestra un santoral que ha de entenderse como un conjunto de "retratos morales" extraídos entre los propios santos monacales ${ }^{21}$. Los pro-

20. A. A. ROSENDE VALDES: La sillería de coro barroca de San Salvador de Celanova. Santiago de Compostela, 1986,12.

21. A. A. ROSENDE VALDES: La sillería..., 123. 
tagonistas de este santoral son, por una parte, "los miembros de la orden de carácter más universal" -Benito, Escolástica, Gertrudis, Mauro, Ildefonso, Anselmo-, por otra, una serie de santos hispanos -San Isidoro de Sevilla, San Veremundo de Irache, San Iñigo de Oña, San Millán de la Cogolla-, y un tercer grupo formado por santos extranjeros: San Lorenzo de Canterbury, San Columbano de Irlanda, San Bonifacio de Inglaterra... ${ }^{22}$.

Debe de tenerse en cuenta, además, que si sobre la silla del abad se ubica la figura del fundador, San Benito, sobre la del prior aparece San Rosendo, el fundador de este monasterio.

En la sillería baja se presenta un ciclo que expone dos historias: las vidas de San Benito -al lado sur- y la de San Rosendo -al norte-. El ciclo dedicado al fundador de la Orden se inspira en los grabados del mismo libro que el coro benedictino compostelano: "Vita et miracula Sanctissimi Patris Benedicti. Ex Libro II Dialogorum Beati Gregorii Papae et Monachi collecta, et ad instantiam Devotorum Monachorum Congregationis eiusdem Sancti Benedicti Hispaniarum aeneis tÿpis accuratissime delelineata", publicada en Roma en $1579^{23}$. También se inspira en este repertorio alguno de los temas relativos a San Rosendo, dada la falta de una serie propia en la que inspirarse ${ }^{24}$.

La traza del coro conoce el arte compostelano. Alguna idea del catedralicio santiagués, así como del coro de San Martiño Pinario - con su remate de Diego de Romay-, y las novedades que han partido de Domingo de Andrade, en el arte santiagués en el último decenio del XVII, se pueden detectar en la obra de Celanova.

Así, los basamentos de las columnas del orden superior de la sillería jacobea pueden inspirar a aquellos sobre los que se asientan las veneras que cubren el santoral orensano en tanto que los influjos rastreables en el cenobio benedictino compostelano son de variada índole; el remate del de Celanova tiene una cadencia similar al de San Martiño y en aquel se inspira su ciclo de las vidas de San Benito y San Rosendo aunque en la obra de Canseco se haya de disponer en la sillería baja dado que no se busca aquí crear una altura tan notable como en Santiago, donde el guardapolvo tiene un nivel de límite que aquí no se busca; ha de recordarse al respecto que arriba hay otro coro, rezando al tiempo, y que ambos conjuntos debe de inscribirse, ambientalmente, en uno solo.

Los débitos con Andrade son, también en este caso, notables. La solución de la venera como remate -en Celanova cubriendo a cada santo- la está planteando el maestro de obras de la Catedral en la parte interior del Pórtico Real de la

22. Cfr. A. A. ROSENDE VALDES: La sillería ..., 73-122.

23. Cfr. A. A. ROSENDE VALDES: La sillería ..., 20-41.

24. Cfr. A. A. ROSENDE VALDES: La sillería ..., 41-72. 
basílica jacobea. El interés por las decoraciones de guirnaldas, telas y otros motivos ornamentales parecen tener también una filiación andradiana.

La obra tudense, llevada a cabo entre 1699 y 1700 bien pudo hacerse, en parte al menos, en Celanova. Como allí cabe ver manos distintas -de un mismo taller- trabajando, que dan un tono diferente, también aquí, a las figuras de los santos -sobre las sillas del nivel superior- y a las escenas, tanto encima de las sillas bajas como en el área del guardapolvo.

Se suman, de hecho, en la obra tudense, las mismas referencias modélicas que en Celanova pero, asumiendo, de los ejemplos tomados, otros aspectos parciales. Está inspirada en el coro de la catedral compostelana, por ejemplo, el modo de entender el entablamento dispuesto sobre el santoral del nivel superior. Tiene que ver, con el de San Martiño, el sentido de ciclo que se le da a las dos alturas de escenas, aún cuando aquí se invierte el orden:pasa la historia de la Virgen para arriba en tanto que la vida del patrono de la diócesis, San Pedro González Telmo, se ubica abajo.

Con Andrade se tienen, también en este caso, deudas que se centran, sobre todo, en el léxico ornamental -cartelas, sartas de frutos...-.

Resulta, por lo demás, novedoso, con respecto a los ejemplos anteriores gallegos, el modo de interpretar los frentes de las pilastras separadoras los santos que cobijan las sillas altas. $Y$ es que ahí se presentan otras figuras de menor tamaño y, encima, una ornamentación en la que se tiende a insistir en formas vegetales, hermanas de las sartas de frutos de Andrade.

Resulta bien cuidada, sobre todo, parte del santoral de la sillería alta, claro está más que nada en la parte relativa a aquellos asientos de condición principal presididos por el que ampara la figura del patrono San Telmo ${ }^{25}$. Varias son las cuestiones que cabe resaltar en el plan iconográfico. Martín González ha destacado la insistencia en presentar un santoral afín a las devociones propiamente galaicas ${ }^{26}$; de este modo acompañan al patrono, Epitacio y Evasio, los primeros obispos de la diócesis tudense. Y ahí están, además, Fructuoso, Rosendo, Pedro de Mezonzo, Froilán, Pelayo, Eufemia, Liberata, Marina...

Pero también ha de reconocerse -al lado de la originalidad de presentar la vida de San Telmo- los valores temáticos intrínsecos en el ciclo mariano. Tal como ha señalado Rosende Valdés, lo medieval aún predomina en el modo de narrar la historia de la Virgen, en un repertorio que tiene especial cuidado en relacionar a María, la titular de este templo, con el apóstol Santiago el Mayor ${ }^{27}$.

25. M. CHAMOSO LAMAS: Tuy. León, $1981,61$.

26. J. J. MARTIN GONZALEZ: Sillerías de coro. Vigo, 1964, 38-39.

27. A. A. ROSENDE VALDES: La vida de la Virgen en la sillería de la Catedral de Tuy: un testimonio iconográfico medieval en el Barroco. "Arte Gótico Postmedieval" Segovia, 1987, 211. 
Presidía la parte alta del coro, antes de ser remodelada su forma, una imagen de la Asunción que hoy se guarda en el museo catedralicio ${ }^{28}$.

Como ya se ha señalado el taller de Castro acomete, al menos, un tercer frente de trabajo desde Celanova que lo lleva a contribuir el proceso de enriquecimiento de la capilla del Santo Cristo. Primero contrata la cúpula que remata su baldaquino; es por 1696 cuando se compromete a llevar a cabo "media naranja de madera con sus molduras y talla para el tabernáculo que está en la Capilla"; según señalan Ferro y Lorenzo, "como complemento de esta obra, al maestro le tocó hacer cuatro ángeles que se colocaron en las esquinas del baldaquino" ${ }^{29}$.

También en 1696 se contratan los altares colaterales que encuadran el arco de ingreso a la zona del baldaquino: " $Y$ en quanto a los colaterales se han de hacer a los lados del arco de la capilla, han de ser doce cuartas de ancho y dieciocho de alto con dos columnas salomónicas cada una con pedestal y cornisamiento tallado... y una caxa con marco tarxeta y arbotantes y dentro de cada caxa una concha y debaxo de la concha un nicho o cueva para una imagen de la Magdalena de suerte que todas las imaxenes estén y queden debaxo de una cortina" 30; en relación con esta obra, en la que hace "mucho más que la planta", se le paga en 1697 y se sabe que, entonces, pasa el maestro diecisiete días en Orense. Es entonces cuando se acuerda completar la obra en torno al arco de ingreso hacia el baldaquino, labor que se paga en 1698 y en la que se disponen una serie de relieves siguiendo unos principios en parte parecidos a los manejados en la capilla mayor de Celanova.

Debe de tenerse en cuenta que, para esta parte del trabajo,toma Castro Canseco, en principio de una planta ajena. Ha de valorarse, además, la circunstancia de que es nada menos que Domingo de Andrade quien había concebido inicialmente la ornamentación de esta capilla ¿Se estarían ahora, al principio de la labor de Castro, siguiendo todavía criterios del maestro de la catedral compostelana?; alguna forma, contratada y no realizada exactamente -el uso de la concha-como cubierta, pueden remitirnos a su gusto que, en cambio, se tiene en cuenta en la obra tudense.

Pero tampoco pueden pasar desapercibidos los paralelismos entre el sentido de la decoración que se puede observar en la valoración barroca de esta capilla y lo que se ha hecho ya en el retablo mayor de Celanova. Como allí los retablos latereles, integrados en una unidad más amplia, se coronan con relieves y la representación de los mismos cielos se aborda en la parte central y alta.

28. F. J. LIMIA GARDON: Virxe da Asunción. “Galicia no Tempo”. Santiago 1991,299.

29. J. FERRO COUSELO, J. LORENZO FERNANDEZ: La Capilla ..., 39.

30. J. FERRO COUSELO, J. LORENZO FERNANDEZ: La Capilla..., 39. 


\section{DESDE 1700, NUEVA ETAPA DE PRODUCCION}

En 1699-1702, se continúan las obras en esta capilla estando presente diferentes oficiales de su taller -un tal Gregorio, Francisco Ribela, Pedro Ribeiro, Ignacio.... ${ }^{31}$.

Los frentes de acción del maestro son, de hecho, sumamente variados; recoge Caramés como, "además de las ganancias por su arte, Castro Canseco procuró, al parecer, otras actividades ajenas a su profesión, pues, vemos como en septiembre de 1710, forma sociedad con D. Juan Antonio de Deza y Mosquera, vecino de Reza, y con D. Ignacio Rodríguez de la Barra, para la cobranza de los votos del Apóstol, en el obispado de Orense, durante dicho año ${ }^{32}$.

Es en 1702 cuando remata la "caja del Señor, Virtudes, Pilastras, Custodia y las dos ystorias de la Cruz"; también se le abonan ahora los temas del Descendimiento, Oración en el Huerto y Cristo a la Columna ${ }^{33}$.

En el año 1703 se le pagan al maestro Canseco "las diez sibilas del corredor, los nichos y sirenas y las dos historias de la reja, 500 reales por 'maestrar' la demás obra de talla que se hizo para el corredor, cuadros y ventana y 100 ducados por seis ángeles" ${ }^{34}$; éstos se iban a colocar encima de las escenas de las representaciones del Descendimiento, Oración en el Huerto y Cristo a la Columna.

En el trabajo de Castro Canseco juega un papel tiene una importancia grande, en este último momento de obra en la ornamentación de esta capilla, esa labor de organizar todo el conjunto de obra -escultórica y pictórica- que se ha ido acumulando, sobre todo en los últimos años, destinada a esta capilla. Así se incluyen una serie de obras que proceden, unas de Madrid ${ }^{35} \mathrm{y}$, otras, de Valladolid ${ }^{36}$; es el caso de la Dolorosa que se dispone a espaldas del Cristo ${ }^{37}$.

El protagonismo del Crucificado se subraya con una temática complementaria que tiende aludir a su culto. En altares secundarios se hace mención a la devoción a los padres de Jesús --José y María-. Por otra parte la temática de las sibilas ha de justificarse desde su condición profética, relacionando el escultor, por medio de atributos, sus diferentes imágenes con alusiones calificables de sacras ${ }^{38}$.

31. J. FERRO COUSELO, J. LORENZO FERNANDEZ: La Capilla .., 41.

32. C. CARAMES GONZALEZ : El escultor ..., 169-170.

33. J. FERRO COUSELO, J. LORENZO FERNANDEZ: La Capilla ..., 41.

34. J. FERRO COUSELO, J. LORENZO FERNANDEZ: La Capilla ..., 41.

35. J. FERRO COUSELO, J. LORENZO FERNANDEZ: La Capilla ..., 61.

36. J. FERRO COUSELO, J. LORENZO FERNANDEZ: La Capilla ..., 62-63.

37. Cfr. A. GARCIA TERRON: Dolorosa. "Galicia no Tempo". Santiago 1991,298.

38. Cfr. J. FERRO COUSELO, J. LORENZO FERNANDEZ: La Capilla ..., 43-44. 
En 1704 Francisco de Castro Canseco firma un importante contrato con los monjes de Oseira, lo que le obligaba a llevar adelante la fábrica de la fachada y portería principal de su monasterio. En el documento pertinente, escrito en Oseira, se reconoce al artista como "Maestro Arquitecto, y vezino de la ciudad de Orense" y como la persona que, de la obra a realizar, "sacó su planta según arte en dos papeles, el primero propuesta la haçera de dicho fronteinspiçio, y en el segundo dichos repartimientos, que mostró a dicho Padre Abbad y monges que, por ser a su satisfaçión quanto a lo que a su bista les toca y perteneçe conoçer, se conformaron..." 39 .

De la obra en cuestión tiene una importancia notable -desde el punto de vista de la traza y la labor escultórica a relacionar con Castro Canseco- la parte relativa a la portada principal. En el citado contrato se dice, al respecto, "que se han de hacer quatro colunas con pedestales y cornisamentos, dos a cada lado de dicha puerta, y en los yntermedios dellas dos efigies las que parecieren a ambas partes más combenientes, con pilastras, tarjetas o escudos para su buen adorno $y$ arquitectura...en lo que toda a la portada se an de haçer tres puertas bentanas para el serviçio del balcón, con sus fajas, mascarones y talla, como parece en su diseño; y en los inttermedios de dichas ventanas se han de haçer quatro pilastras baçiadas al plomo de dichas columnas, con sus bassas, capiteles y cornisamento, y ençima de la principal puerta bentana se ha de hacer un escudo de armas reales con su corona ymperial orleado..." ${ }^{40}$.

Como puede verse, la obra de la portada fue remodelada, en altura, unos años después y no siguió estrictamente lo previamente descrito en las columnas salomónicas, de la parte baja, y en el sentido que le da a los relieves que se disponen en la parte baja; en ellos se hace, en uno alusión a San Benito como ermitaño recibiendo la ayuda de San Román, en otro, un sueño de San Bernardo el día de Navidad. Y si bajo el fundador del Cister se dispone otro relieve alusivo a San Ero sobre el relativo a San Benito se presenta un motivo de naturaleza decorativa. Por último, sobre la puerta, hay dos alegorías que hacen referencia al triunfo sobre las tentaciones y sobre la muerte, refiriéndose, pues, al ideario monástico, en interpretación de Limia. ${ }^{41}$.

Existe, por otra parte, una cierta relación de esta obra de Canseco, sobre todo en lo ornamental, con Domingo de Andrade. Sin embargo no debe de pasar desapercibida la preocupación que aquí se detecta, sobre todo, por lo escultórico en tanto que se observan ciertas deficencias en el desarrollo de la traza; nótese,

39. F. J. LIMIA GARDON: El autor de la fachada del monasterio cisterciense de Santa María la Real de Oseira (S. Cristóbal de Cea-Ourense). "Porta da Aira", II (1989), 96-97.

40. F. J. LIMIA GARDON: El autor ..., 98.

41. F. J. LIMIA GARDON: La arquitectura barroca en el monasterio de Oseira. Tesis de Licenciatura inédita (Santiago, 1985), págs 157-159. 
por ejemplo, como no se atiene al dictado del contrato en su deseo de que las pilastras que estructuran las ventanas se dispongan en línea con respecto a las columnas de la parte baja.

Se hacen también otras precisiones en el contrato, relativas a la generalidad de la fachada, dignas de ser tenidas en cuenta: "Que todo el paramento de la fachada que mira a la parte del norte, yncluyendo la fachada de la torre, ha de ser almoadillada en correspondencia del frotte eispicio de la yglesia. Que ha de coronar dicha obra el floreo que representa la dicha planta, y ençima, en lo que corresponde a la puerta y balcón principal, en lo más elevado se ha de poner una estatua de Nuestra Señora de la Asumpción, como pide dicho misterio,y, encima de las pilastras más inmediatas, dos estatuas de los Padres San Benito y San Bernardo..." 42 . Las pretensiones señaladas demuestran, pues, la calidad retablística que se le quiere imponer a la portada propiamente dicha, con una labor escultórica que pusiese en valor las posibilidades del taller de Canseco quien aparece en 1705 citado en las cuentas del Santo Cristo de Ourense de la siguiente forma: "El Maestro Castro trujo de Osera 12 rs. para la Capilla" ${ }^{43}$.

Ya en abril de 1708 contrata un retablo para la capilla que la Hermandad de Nuestra Señora del Rosario tenía aneja a la iglesia del convento de Santo Domingo de Orense; se acuerda "que la dicha capilla se bista y adorne con un retablo que cubra y adorne todo el típano de ella desde la mesa del altar hasta el parinudillo que llaman artesonado"; en ese mismo documento se compromete el artista a hacer la imagen de Nuestra Señora del Rosario, "de escultura de cuerpo entero, con el Niño en el braço izquierdo y en la mano derecha su rosario, con su peana muy garbosa y coronas a dicha imagen y el niño". Por lo que se refiere al retablo se dice que, "en los cinco óbalos que demuestra la traza, en el segundo cuerpo, se an de poner los cinco misterios gloriosos". Caramés identifica lo que queda de este retablo dentro de la iglesia domínica, "en el lienzo inmediato al lado del Evangelio del Altar mayor" ${ }^{44}$; también se encuentra aquí la citada imagen del Rosario, "de canon muy esbelto, y recuerdo lisipianos, aunque de indudable progrenie manierista" ${ }^{45}$.

Por 1709 Casto Canseco lleva a cabo dos nuevas obras para la iglesia de los domínicos orensanos: el retablo mayor y el existente al lado de la epístola que pertenece a la cofradía de San Jacinto; hasta hace poco tiempo este último retablo se ubicaba en una capilla propia de la mencionada cofradía ${ }^{46}$.

42. F. J. LIMIA GARDON: El autor..., 98.

43. J. FERRO COUSELO, J. LORENZO FERNANDEZ: La Capilla ..., 41.

44. C. CARAMES GONZALEZ : El escultor ...,178.

45. F. J. LIMIA GARDON: Virgen del Rosario, en Galicia no Tempo. Santiago de Compostela, 1991,300 .

46. C. CARAMES GONZALEZ : El escultor ...,180. 
El retablo mayor de Santo Domingo participa de una estructura con tres calles en su cuerpo inferior, centrado por una gran hornacina que preside una imagen de la Virgen del Rosario, y un gran relieve en el medio de su cuerpo alto, enmarcado entre ventanas; se muestra aquí una Virgen con el Niño ante los que están orantes Santo Domingo y Santa Rosa.

Volverá este artista a tener un encargo de la catedral de Orense. Es, por entonces, cuando va a llevar a cabo las cajas grande y pequeña de sus órganos; él fue autor de las correspondientes trazas ${ }^{47}$; tal obra aparece recogida ya como hecha entre las partidas de $1713^{48}$. González Paz localiza sobre la puerta norte del crucero catedralicio un grupo de Santiago ecuestre que reconoce como remate de la caja grande ${ }^{49}$; debe de tenerse en cuenta el paralelismo temático que existe entre este grupo y el que ultima la caja del órgano del lado norte de la catedral de Santiago, precedente tenido en cuenta, sin duda, por este maestro.

El monasterio de Celanova también le va a encargar, por 1710, la caja de su órgano. Señala Couselo que, según el contrato, "se haría según la planta dada, con talla, cuyas dimensiones serían el espacio de una a otra pilastra y de alto hasta la bóveda" ${ }^{50}$; posiblemente deban relacionarse con Castro Canseco los ángeles trompeteros que se sitúan rematando la caja del órgano actual, planteado ya desde formulaciones rococós que exigen una cronología más tardía a la de este maestro.

En ese año de 1710 hay una nueva noticia que señala su vinculación a Melide; $\mathrm{da}$, por entonces un poder para que su hermano Alonso de Castro cobre "lo que sus caseros y colonos le están debiendo en los lugares del Ribeiro,Petos y demás que el otorgante tenía "en aquellos parajes"" 51.

Será en 1711 cuando la Cofradía de la Vera-Cruz, del convento de San Francisco de Ourense, le contrata unos pasos para que "con la dezencia devida y con permanencia representasen la Pasión de Nuestro Redentor y Salvador Jesucristo en las dichas procesiones del Jueves Santo" ${ }^{52}$.

Hace unos años se desmontó el retablo que, por 1712, contrató Castro Canseco para la iglesia de Santo Domingo de Ribadavia. Se pormenoriza documentalmente el modo en que debía de ser llevado a cabo:"Que dicho retablo se ha de hacer en forma pentagonal, como esta la capilla con seis columnas salomónicas

47. P. PEREZ COSTANTI: Diccionario..., 96.

48. C. CARAMES GONZALEZ : El escultor ...,175.

49. J. GONZALEZ PAZ : Santiago el Mayor en la imaginería orensana. "Compostellanum", 2, X (1965), 380 .

50. J. COUSELO BOUZAS: Galicia Artística en el siglo XVIII y primer tercio del XIX. Santiago, 1933, 261.

51. C. CARAMES GONZALEZ : El escultor ..., 187.

52. C. CARAMES GONZALEZ : El escultor ..., 183. 
en el primer cuerpo con su pedestal y cornisa... se ha de hacer una caja grande en el medio de dicho retablo, en el primer cuerpo, a donde se ha de colocar Nuestra Señora del Rosario, nuestro Padre Santo Domingo y Santa Cathalina de Sena, que an de estar de rodillas, tomando los rosarios las dos ymágenes de manos de Nuestra Señora y su santísimo hijo, y asimismo se han de fixar otras cuatro cajas en los intercolumnios, a donde se han de poner cuatro santos de bara y media de alto... al nivel de la caja de Nuestra Señora se ha de hacer una custodia con dos columnas arbotantes con su cornija y tajeta con las tres virtudes... en el segundo cuerpo, en el remate, que es el que cierra la bóveda y el plomo de la caja de Nuestra Señora se ha de hacer otra caja capaz para un Santo Cristo de vara y media y se han de guarnecer los rampantes de la bóveda con todas sus lunetas... dejando quatro ochavos, quatro ventanas para la luz del tamaño que pareciere más conbeniente.." 53.

La traza convenida para la obra de Ribadavía se adapta plenamente a los criterios usualmente mantenidos por Castro y su realización siguió lo indicado.

En 1714 figura su nombre en las cuentas de la catedral orensana; es entonces cuando se le paga el retablo de San Miguel, a la derecha de la puerta sur del crucero; se adapta a las formas usuales del maestro ${ }^{54}$.

El contrato suscrito con la comunidad benedictina de Celanova en $1714^{55}$ trata sobre la realización del retablo del altar colateral del Santísimo Cristo (lado norte) y del arreglo del también retablo colateral de Nuestra Señora (lado sur) que habría de rematarse de acuerdo con la obra a realizar en el del Santísimo Cristo. Ello parece suponer un trabajo previo, inacabado, de Canseco en el retablo de la Virgen. Parte de la imaginería que aquí puede verse debe de relacionarse con el maestro: la figura de San José, los ángeles existentes, en el nivel superior de ambos conjuntos, así como el Salvador que se encuentra en la parte superior, en el centro, del retablo del Santo Cristo ${ }^{56}$.

Debe de señalarse, por otra parte, que estos retablos ahora rematados concuerdan perfectamente con el formato y grandiosidad del que preside la iglesia.

También por 1714 Castro Canseco contrata una obra en Compostela. Nada menos que las monjas benedictinas de San Paio son las que le llaman. En la portería del monasterio santigués firma un documento que, después se elevará a público en Ourense. Por él "llenaría el altar todo el ancho y alto de la pared de la capilla mayor, sobre un pedestal de cantería que correría a cuenta del mismo

53. C. CARAMES GONZALEZ : El escultor ..., 180-182; muestra también una fotografía de esta obra.

54. C. CARAMES GONZALEZ : El escultor $\ldots, 175$.

55. Cfr. C. CARAMES GONZALEZ : El escultor ..., 184.

56. C. CARAMES GONZALEZ : El escultor ..., 184. 
maestro, dejando puertas para la sacristía, y en una de ellas a respaldo del retablo haría una escalera de madera que llegase hasta el camarín de Nuestra Señora, en disposición para que por ella se pudiese subir a todas las partes del retablo. Lo daría asentado el $1^{\circ}$ de Septiembre de 1716 , siendo condición precisa que el maestro montase el taller para la construcción del mismo, en una distancia intermedia entre Puente Ledesma y la ciudad de Santiago, para poder vigilar su construcción el monasterio por medio de una persona a este fin destinada. Se le daría por la obra, de castaño o nogal, de buena calidad, con las imágenes indicadas en la planta, 55.000 reales" 57 .

La realización de este retablo le lleva a tener en cuenta ya no solo las propuestas, como tracista, de Andrade. Concretamente han de tenerse en cuenta, ahora, las sugerencias que, al respecto, le puede hacer la obra de Miguel de Romay quien, precisamente en ese año de 1714, acaba de montar el retablo mayor de la compostelana capilla de la V.O.T., en el que pueden verse una serie de fórmulas similares a las que ahora desarrolla Canseco sin, por ello, dejar, aquellas notas más significativas de su estilo. Así, su modo de valorar las escenas, por medio de relieves de notable dimensión, se presenta, también aquí, en la escena alusiva al martirio de Pelayo que se recoge en la parte central, a la altura de los capiteles de las grandes columnas salomónicas.

Aún cuando una parte de la imaginería de este retablo sea ajena a su taller no - debe de estar, en cambio, fuera de los criterios argüidos en la traza original. Esa presencia de dinámicos grupos ecuestres, presente en la parte alta del retablo, tiene su antecedente en el quehacer del propio Canseco, allá en el retablo mayor de Celanova.

La catedral de Ourense insiste, en los siguientes años, en tener a Castro Canseco como artista de su confianza: "En las cuentas de Fábrica de la catedral de 1716 se consignan 7.236 reales para cuenta de los dos retablos de la capilla mayor dedicados a los Santos Mártires ; y en las de 1717-1718, 4.774, resto de los 12.000 en que fueron ajustados los retablos de San Facundo y Primitivo. En las de 1718-19 hay una data de 1.300 reales por la hechura del altar de la Resurrección; y en esta misma fecha aparece hecho el de Santa Eufemia" ${ }^{58}$.

Debe valorarse, en este conjunto de obras llevadas a cabo en la catedral ariense, su interés por adecuar a los nuevos tiempos el ornato no solo de la capilla mayor sino también de su entorno inmediato, concretamente en la girola.

Y es que la obra que se plantea en este caso Canseco tiende a incrustar el antiguo retablo del XVI en un conjunto ornamental más amplio, que sitúa a cada uno de sus lados un nuevo altar, con un elaborado plan retablístico encima que 
alude, en un caso, a Santa Eufemia, y en el otro a los Santos Facundo y Primitivo; se conciben estos dos nuevos trabajos desde una doble faz ya que, un nuevo altar y retablo se presentan, con las mismas devociones, mirando hacia la girola. Se practica, pues, una especie de "horror vacui" que tiene sus precedentes en esta misma catedral en la capilla del Santo Cristo.

Por lo que se refiere a los retablos citados que se disponen hacia la girola debe de señalarse su alejamiento de las fórmulas usuales en Canseco; ello se explica teniendo en cuenta que trabaja, en este caso, con trazas ajenas, tal como señala Caramés desde la lectura del correspondiente contrato ${ }^{59}$.

En el declinar vital de Castro Canseco ha de situarse el trabajo que lleva a cabo para la capilla de la Resurrección, en el deambulatorio de la catedral orensana. Una escena de buen tamaño, con el tema que da título a la capilla, preside el conjunto; sigue, en cierta medida, la pauta marcada por Mateo de Prado en otras capilla de esta misma zona catedralicia.

Castro Canseco aún hubo de preocuparse de otros menesteres en esta Catedral. Debe de relacionarse con su taller el retablo de Nuestra Señora de Belén, en que se integra una tabla, como predella, con una Huida a Egipto - a relacionar con el círculo de Mateo de Prado-, que debe de considerarse una pieza previa que se adapta, en este caso, a un nuevo marco ${ }^{60}$.

La última etapa de su vida, con sus estrecheces económicas, se pueden vislumbrar desde lo que se recoge en un pleito, de 1722. Lo promueve un oficial suyo, Salvador Cebreiro que, según su declaración, es oficial de Arquitectura; lleva a cabo su reclamación ante el maestro porque le había prestado a éste 192 reales para hacer la vendimia y le debía, además, el salario de 289 días; se cita, concretamente, que "había trabajado en el taller de Castro para las obras de los conventos de S. Francisco y Sto. Domingo" ${ }^{61}$. Y, al aludirse a los testigos, se enumera a otros oficiales que se vinculan, en su quehacer pasado al lado de Casto, a diversas obras entre las que se señala "la fábrica del retablo que se hizo para la capilla mayor del convento de San Francisco".

En relación con el retablo de San Francisco de Orense se sabe que tenía "tres imágenes de Santos de bulto, la una del glorioso San Miguel, en quinientos y quarenta reales, otra echura de Santa Lucía, en cien reales y otra más de San Caetano, en ciento y veinte reales... quarenta reales por una traça" ${ }^{62}$.

59. C. CARAMES GONZALEZ : El escultor ..., 175.

60. J. HERVELLA VAZQUEZ: Posible representación de la ciudad de Orense en una "Huida a Egipto". "Nadal de Ourense", 0 (1989), 28.

61. C. CARAMES GONZALEZ : El escultor ..., 170.

62. C. CARAMES GONZALEZ : El escultor ..., 183. 
Esta debió de ser su última obra para los franciscanos de Ourense; poco antes, quizás, había construido su coro, obra de escaso valor artístico ${ }^{63}$.

La impronta de Francisco de Castro Canseco debió de ser notable en la provincia orensana, en donde cabe citar obras que se han reconocido dentro de su círculo; es lo que sucede, por ejemplo, con el retablo de San Salvador de Sande que se ha encuadrado dentro de este contexto ${ }^{64}$.

63. C. CARAMES GONZALEZ : El escultor ..., 182.

64. J. C. FERNANDEZ OTERO, M. A. GONZALEZ GARCIA, J. GONZALEZ PAZ : Apuntes para el inventario del mobiliario litúrgico de la diócesis de Orense. Vigo, 1983, 115. 


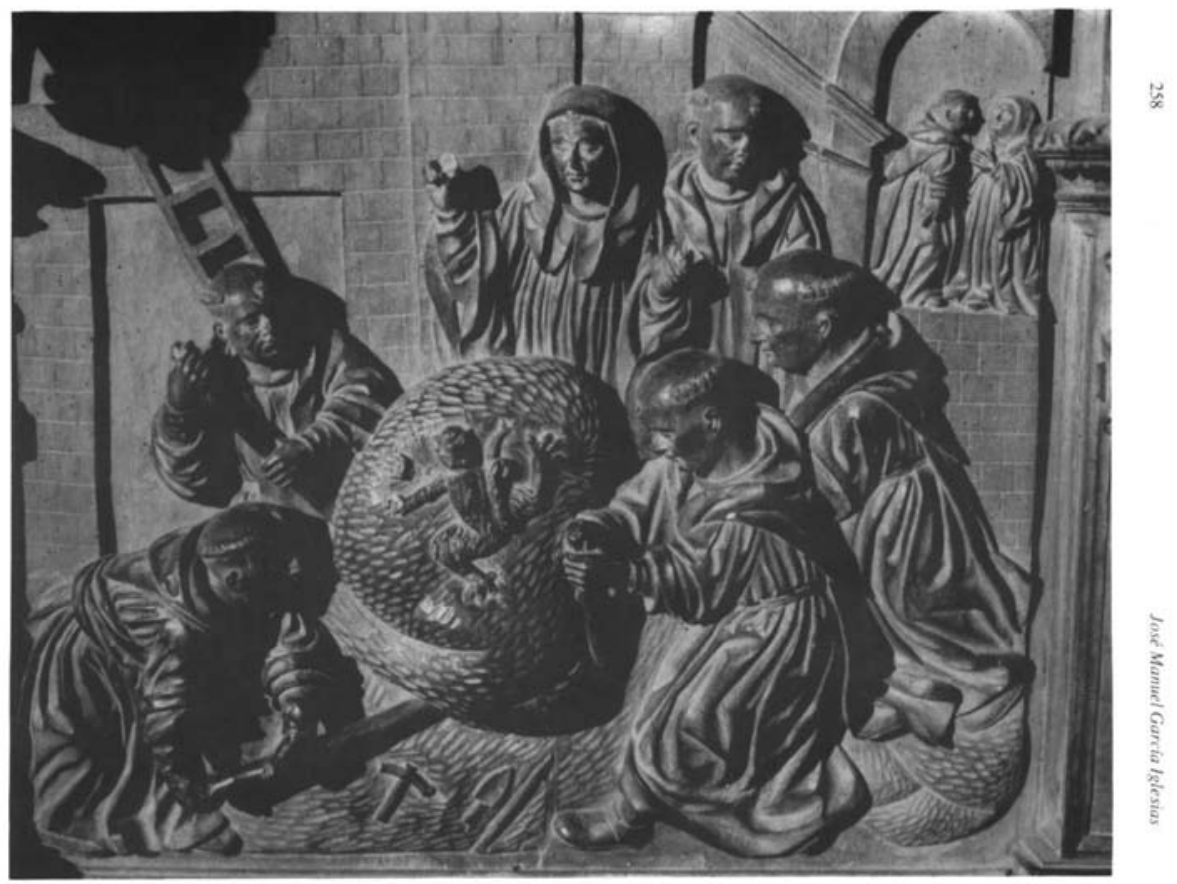

1. Monasterio de Celanova. Sillería de coro. "La piedra aligerada de su peso". 


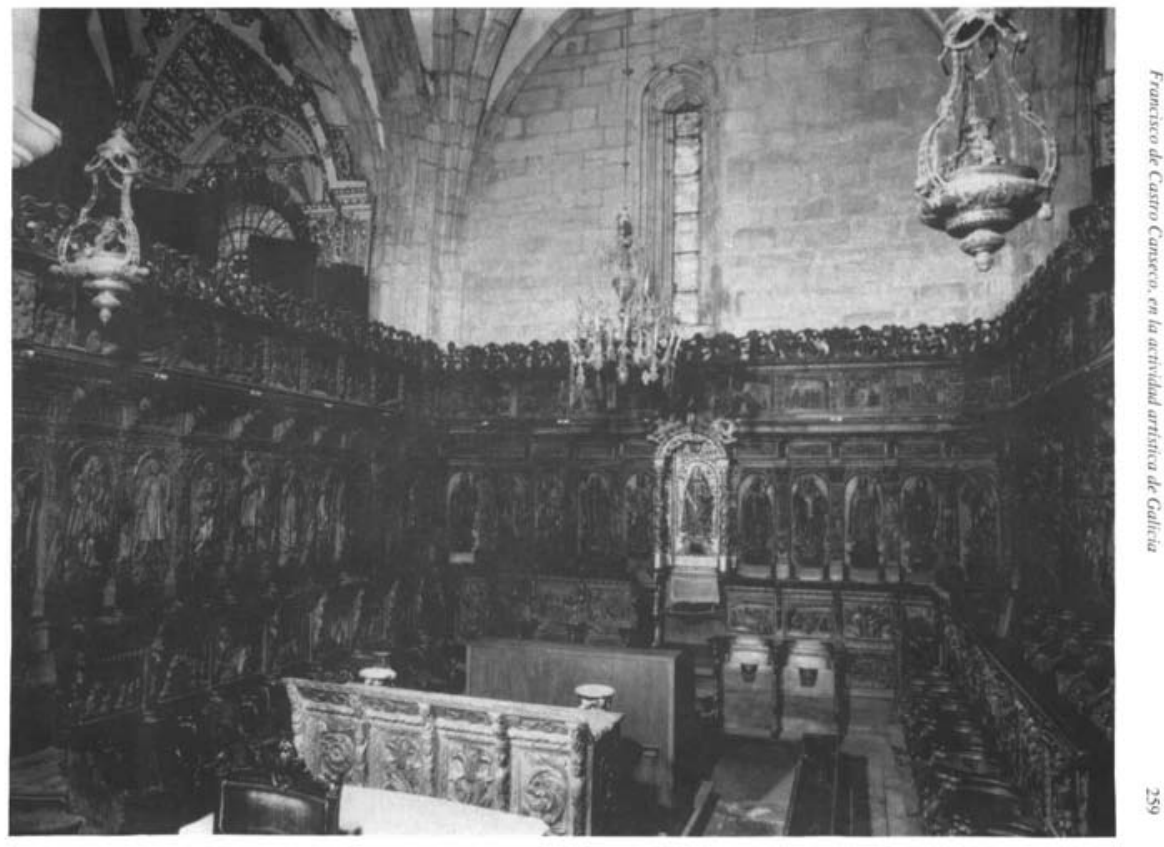

2. Catedral de Tui. Sillería de coro. 


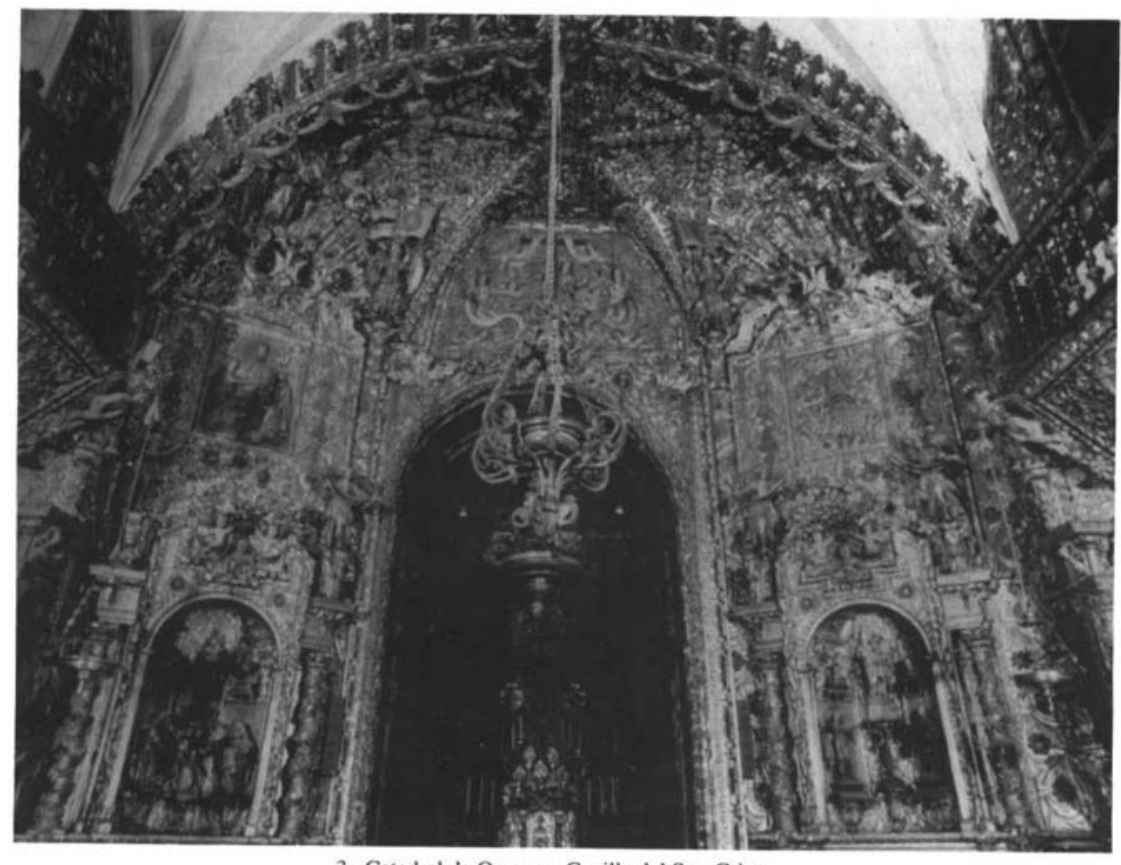

3. Catedral de Ourense. Capilla del Sto. Cristo. 


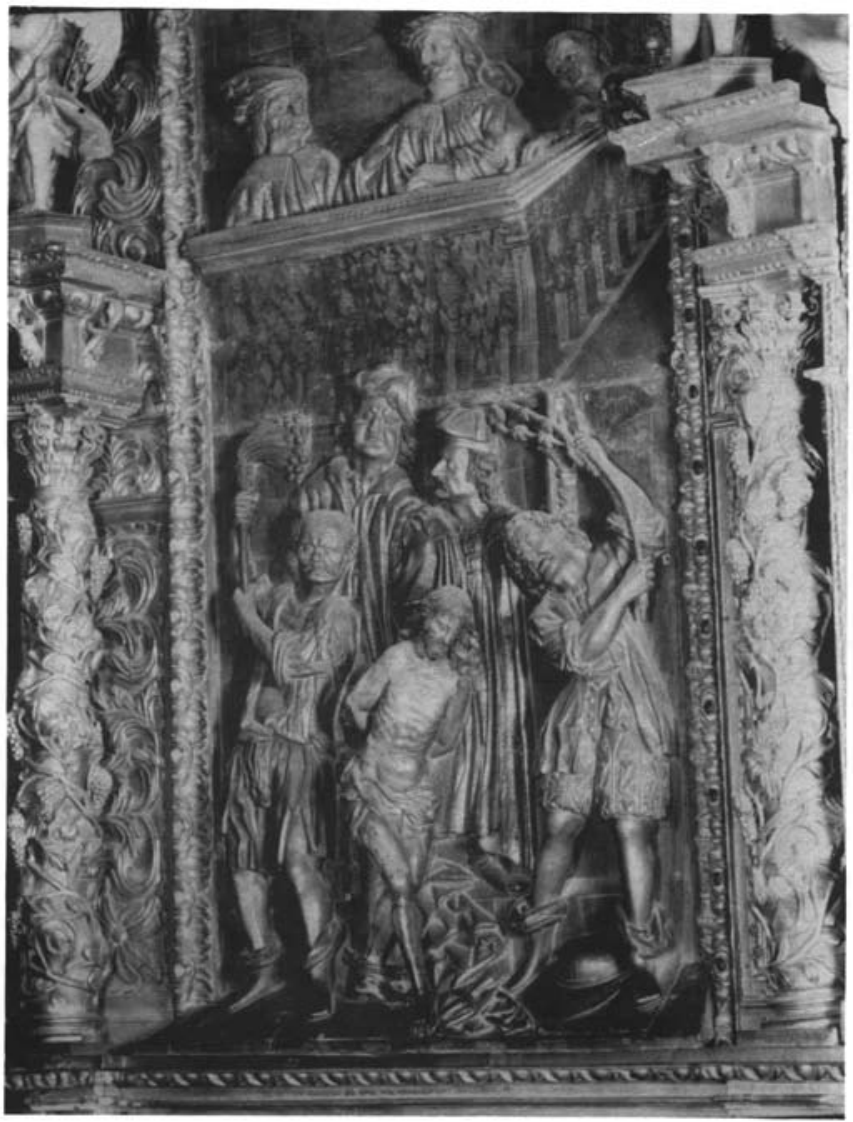

4. Catedral de Ourense. Capilla del Sto. Cristo. "La Flagelación". 


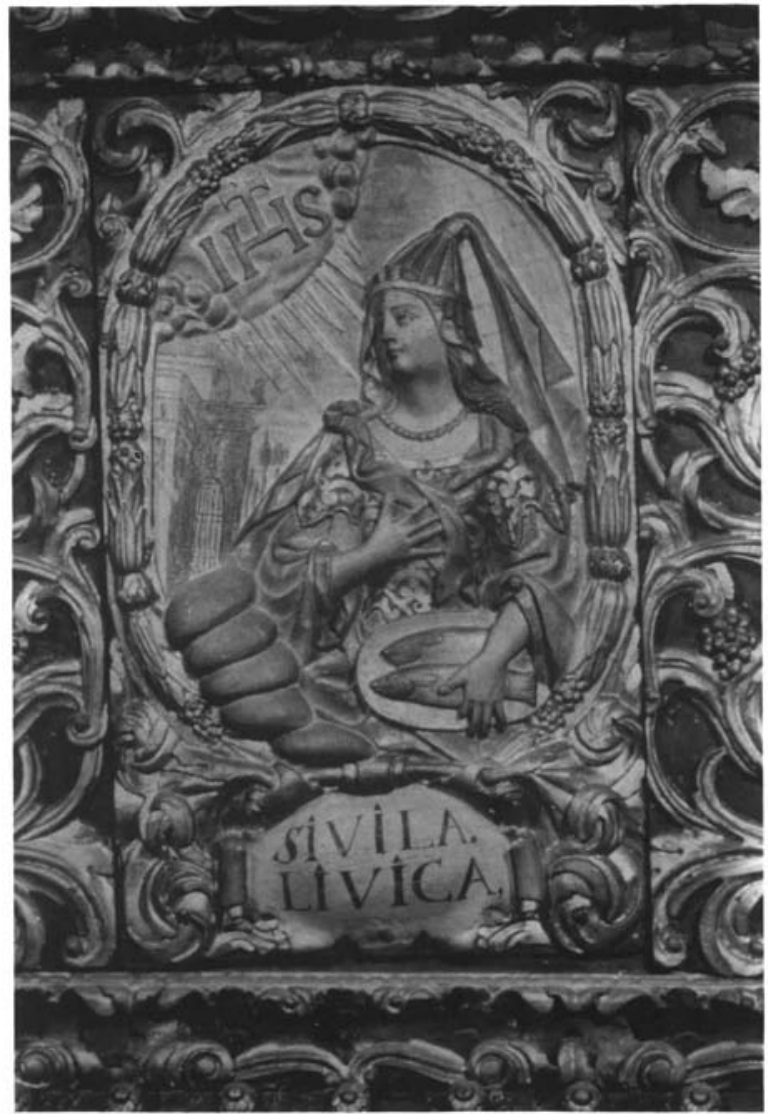

5. Catedral de Ourense. Capilla del Sto. Cristo. "Síbila Líbica". 


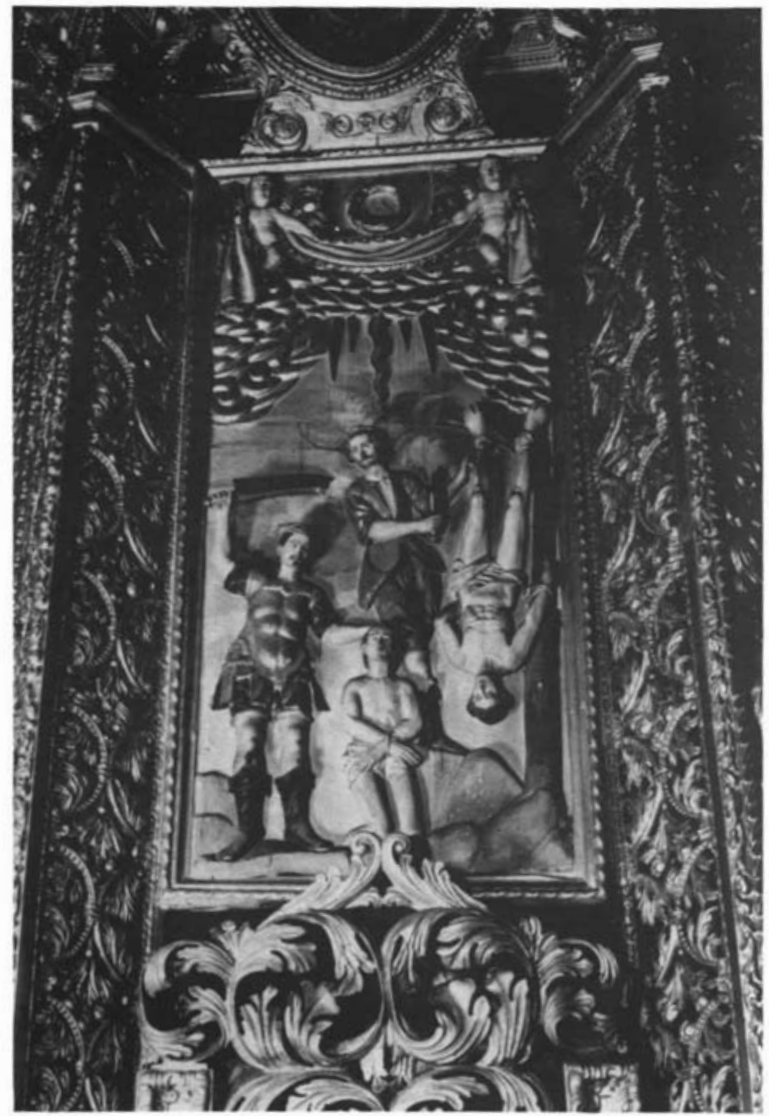

6. Catedral de Ourense.

Capilla Mayor. Martirio de los Santos Facundo y Primitivo. 